\title{
The Need for Open-access Structured Data in Cardiology Research
}

\author{
Alessandro Pingitore $^{a}(\bowtie)$, Clara Carpeggiani $^{a}$ \\ a National Research Council, Institute of Clinical Physiology, Pisa, Italy \\ https://www.ifc.cnr.it/index.php/en/
}

\section{ARTICLE INFO: \\ ReCEIVED: 21 Sep 2014 \\ REVISED: 05 Nov 2014 \\ ACCEPTED: 12 Dec 2014 \\ ONLINE: 06 Jan 2015}

\section{KEYWORDS:}

Open Acess

Cardiology Research

Cardia Registries

Structured Scientific Data

\begin{abstract}
A BSTRACT
Sharing research data represents the new challenge of the scientific communities in order to facilitate communications among researchers, the dissemination of the scientific ideas and products, the refinement of patient selection for randomized clinical trials, and also to standardize clinical care procedures. The cardiac registries are extensively adopted and oriented both to one specific cardiac disorder and to overall cardiac disease. In 1982 the CNR Institute of Clinical Physiology implemented an institutional database to store the most important clinical and instrumental data obtained during patient hospitalization. Thanks to the large amount of data many scientific datasets were published on prognosis, epidemiology and health care procedures. Finally, research data sharing also provide the opportunity to approach cardiac research studies in an integrated, multidisciplinary and systematic framework.
\end{abstract}

Creative Commons BY-NC-SA 4.0

EY NC SA Creative Commons BY-NC-SA 4.0

C 2015 Hosting by Procon Ltd. All rights reserved.

In the last decades, the opening of the scientific communities toward the non-scientific circles represents a challenge. This results from several needs and opportunities: 1) to facilitate communication among researchers on the basis of a uniform framework of scientific data which is semantically and syntactically interchangeable across computer networks; 2) to facilitate dissemination of the scientific ideas, products and by-products to different potential stakeholders, i.e. clinicians, scientific communities, health providers, pharmacological and bio-techno industries; 3 ) to facilitate the refinement of patient selection in order to maximize outcomes with current and new device options; 4) to standardize clinical care procedures.
The roads to solving this challenge are the open access journal and research data sharing. With regard to the open access journal John Willinsky writes: "Wide circulation adds value to published work; it is a significant aspect of its claim to be knowledge. The right to know and the right to be known are inextricably mixed. Open access can benefit both a researcher-author working at the best-equipped lab at a leading research university and a teacher struggling to find resources in an impoverished high school." ${ }^{1}$ This was proved by the fact that freely available online science proceedings garnered more than three times the average number of citations received by print. ${ }^{2}$ 
Concerning data sharing, the implementation of clinical and research registries is the basis of evidence-based medicine. The cardiac registries are extensively adopted and oriented both to one specific cardiac disorder and to overall cardiac diseases. The Registry on Cardiac Rhythm Disorders Assessing the Control of Atrial Fibrillation (RECORDAF) and the Global Registry of Acute Coronary Events (GRACE) are examples of cardiac disease dedicated registries, whereas The National Cardiovascular Research Infrastructure (NCRI) project was initiated with the major objective of creating a model framework for standard data exchange in clinical research, clinical registry, and patient care environments. ${ }^{3-5}$ The studies derived from well-designed and well-conducted medical device registries provide a real-world view of clinical practice, patient outcomes, safety, comparative effectiveness and cost effectiveness and may strengthen a number of evidence.

In this context, in 1982 the CNR Institute of Clinical Physiology implemented an institutional database, called IMAGE, to store the most important clinical and instrumental data obtained during hospitalization of patients affected by cardiovascular disease, mainly heart failure and coronary artery disease. These data include anamnestic information, biohumoral data and instrumental data from different laboratories (ergometry, echocardiographic, nuclear medicine and hemodynamic labs) subsequently enriched with follow up data collected once per year for at least ten years. This has provided a large amount of data essential 1) to obtain clinical data integration useful for playback consultation for health care or research purposes; 2) to obtain epidemiological information on diseases; 3) to follow the different impact of therapeutic procedures on prognosis. Many scientific papers were published in important peer-reviewed journals on the feasibility, safety, diagnostic accuracy and prognostic power of stress echocardiography, the prognostic value of different biohumoral parameters in patients with coronary artery disease and heart failure, the prognostic effect of abnormal thyroid metabolism in patients with cardiac disease, in particular with ischemic and non-ischemic heart failure. .-8 $^{6}$ This last argument, the thyroid-heart relationship, points out also the importance of the multidisciplinary and systemic approach to cardiac diseases. This is fundamental in the light of the evidence that the heart is a part of the amazing integrated system, that is the human body, and it cannot be considered an island but a fully integrated element of this system. As a matter of fact, heart failure can be considered a systemic disease that starts as an organ (cardiac) disease and progresses to a systemic disease involving other organs (kidney, brain, muscle, liver) and endocrine systems.

Therefore, sharing data among researchers with different expertise means also to approach disease studies in an integrated, multidisciplinary and systemic framework which is a new and intriguing road to scientific knowledge.

\section{Acknowledgement}

The preparation of this manuscript was supported by the EU-funded project OpenScienceLink (Grant agreement 318652).

\section{References}

1 Willinsky, J. The Access Principle: The Case for Open Access to Research and Scholarship. Cambridge, MA: MIT Press;2006.

2 Lawrence S. Free online availability substantially increases a paper's impact. Nature. 2001 May 31;411 (6837):521. DOI: 10.1038/35079151.

${ }^{3}$ Camm AJ, Breithardt G, Crijns H, Dorian P, Kowey P, Le Heuzey JY, Merioua I, Pedrazzini L, Prystowsky EN, Schwartz PJ, Torp-Pedersen C, Weintraub W. Real life observations of clinical outcomes with rhythm-and rate-control therapies for atrial fibrillation RECORDAF (Registry on Cardiac Rhythm Disorders Assessing the Control of Atrial Fibrillation). J Am Coll Cardiol. 2011; 58(5): 493-501. DOI: 10.1016/j.jacc.2011.03.034.

4 McAllister DA, Halbesma N, Carruthers K, Denvir M, Fox KA. GRACE score predicts heart failure admission following acute coronary syndrome. Eur Heart J Acute Cardiovasc Care. 2014 Jul 1. DOI: 10.1177/ 2048872614542724.

${ }^{5}$ Anderson HV, Weintraub WS, Radford MJ, Kremers MS, Roe MT, Shaw RE, Pinchotti DM, Tcheng JE. Standardized Cardiovascular Data for Clinical Research, Registries, and Patient Care: A Report from the Data Standards Workgroup of the National Cardiovascular Research Infrastructure Project. J Am Coll Cardiol. 2013 May 7;61(18):1835-46. DOI: 10.1016/j.jacc.2012.12.047.

${ }^{6}$ Carpeggiani C, Landi P, Michelassi C, Barberini E, L'Abbate A. Long-term prognosis in stable angina; medical treatment or coronary revascularization in patients younger than 70 years? Int J Cardiol. $2011 \mathrm{Apr}$ 1;148(1):43-7. DOI: 10.1016/j.ijcard.2009.10.020.

7 Pingitore A, Picano E, Varga A, Gigli G, Cortigiani L, Previtali M, Minardi G, Colosso MQ, Lowenstein J, Mathias W Jr, Landi P. Prognostic value of pharmacological stress echocardiography in patients with known or suspected coronary artery disease: a prospective, large- 


\section{Pingitore A \& Carpeggiani C. Biomed Data J. 2015; 1(1): 36-38}

scale, multicenter, head-to-head comparison between dipyridamole and dobutamine test. J Am Coll Cardiol. 1999 Nov 15;34(6):1769-77. DOI: 10.1016/S07351097(99)00423-4.
8 Pingitore A, Landi P, Taddei MC, Ripoli A, L'Abbate A, lervasi G. Triiodothyronine levels for risk stratification of patients with chronic heart failure. Am J Med. 2005;118:132-136. DOI: 10.1016/j.amjmed.2004.07.05 2. 